\title{
P0172
}

\section{SMART POLYGON AT VSB - TU OSTRAVA 24 H/DAY USING OF PUBLIC LIGHTING NET}

Tomas Novak et al.

DOI 10.25039/x46.2019.PO172

from

CIE x046:2019

Proceedings

of the

29th CIE SESSION

Washington D.C., USA, June 14 - 22, 2019

(DOI 10.25039/x46.2019)

The paper has been presented at the 29th CIE Session, Washington D.C., USA, June 14-22, 2019. It has not been peer-reviewed by CIE.

(C) CIE 2019

All rights reserved. Unless otherwise specified, no part of this publication may be reproduced or utilized in any form or by any means, electronic or mechanical, including photocopying and microfilm, without permission in writing from CIE Central Bureau at the address below. Any mention of organizations or products does not imply endorsement by the CIE.

This paper is made available open access for individual use. However, in all other cases all rights are reserved unless explicit permission is sought from and given by the CIE.

CIE Central Bureau

Babenbergerstrasse 9

A-1010 Vienna

Austria

Tel.: +4317143187

e-mail: ciecb@cie.co.at

www.cie.co.at 


\title{
SMART POLYGON AT VSB - TU OSTRAVA 24 H/DAY USING OF PUBLIC LIGHTING NET
}

\author{
Tomáš Novák, Lukáš Šoustek, Radek Martinek, Jan Látal, Karel Sokanský, Radim Kunčický, \\ Lumír Kunčický, Jan Baroš \\ Department of Cybernetics and Biomedical Engineering, Faculty of Electrical Engineering and \\ Computer Science, VSB-Technical University of Ostrava, Ostrava, CZECH REPUBLIC \\ tomas.novak1@vsb.cz, lukas.soustek@vsb.cz,radek.martinek@vsb.cz, jan.latal@vsb.cz, \\ karel.sokansky@vsb.cz,kun0009@vsb.cz, lumir.kuncicky@vsb.cz, jan.baros@vsb.cz
}

DOI 10.25039/x46.2019.PO172

\begin{abstract}
Article is focused on describing philosophy andpotentialof public lighting network on testing polygon University of Báňská. The main idea is using continuous $24 \mathrm{~h}$ electric power (at this time public lighting use average $12 \mathrm{~h}$ of lighting) for extension functionality of public lighting network using idea of "smart city". The project on which the article is based is focused on testing of light and technical parameters and on implementation of "smart devices" within renewal of the existing city lighting system.
\end{abstract}

Keywords:Public lighting (PL), Wireless communication using light (Broadband light)

\section{Introduction}

Sometimes we are thinking of how it will be living in the future, using newest technologies and inventions the world offers us. How it will be walking down the street and having wireless network internet connection available literally at every corner, when my mobile phone or electric scooterdischarge I am able to charge it back easily plugging it in the socket on public street light, of course after logging on my ID or payment card. When I take my kids to the playground in the park, I know that they are safe and I am able to leave them alone for a while because camera safety system supervise them with function of analyse potential emergency speeches. Similar road traffic, if I will drive throw the city using shared electric car, the car itself will automatically inform me not only about what is happeningon road before me but also about unpredictable behaviour of every single car before me (emergency braking / evasive manoeuvre) and automatically change speed with regard to the surrounding conditions. For those which don't like street light shining at night time,this problem solved automatic regulation of light intensity, when empty street can shine on minimal environment friendly value or can be turned off, when car drive throw the street or when the man walk in lights can turn on only at the nearest area of the moving object, not all the street.

On these and many others project are now working scientists of University of Báňská, technical university of Ostrava. Within the project Test polygon Broadband light on parking of Faculty of Electrical Engineering and Computer Science they are testing possibilities of potential of street light network for inclusion in the concept of "smart city"

\section{Basic philosophy of polygon}

Utilization of PN 24h a day (unlike actual approximately $12 \mathrm{~h}$ ) and the possibility of power up additional devices / sources using PN.

- Camera safety systems

- Possibility of using PN for data transfer (high speed data connectivity in area of all PN Broadband over Powerline Communication )

- Possibility of dynamic light intensity control with demand of actual road traffic based on camera system

- Connection and complex using IP camera system as part of security system in city 
- The readiness of the public lighting network for realization of "smart city“ concept, car to car communications, ...

Public street light polygon is built on university ground. Parts of polygon are 10 public street light poles which provide lighting on 3 types of road (one sided, bilateral, alternating, crosswalk and two separate light points). The entire network is controlled by optical fiber communication, mobile data communication and communication using power line.

The network is opened not only for different light sources but also for different communication and safety technologies.

\section{Polygon equipment}

The polygon is equipped with luminaires Naica, R2L2, Teceo. These LED luminaires are equipped with regulated ballast devices. The parking is illuminated with 3 piecesof Boos Naica, 6 pieces of Thorn R2L2, 5 pieces of Artechnic-SchrederTeceo and 2 pieces of crosswalk lights Artechnic-SchrederTeceoFigure. 1. Another two lights aresituatedin the upper corner ofparking. These luminaires are used fortesting new functionalities and they are developer with cooperation of VŠB-TUO.

Lighting system with lights Naica isdesigned as one sided. System with lights Thorn as bilateral and system with lights Teceo as alternating (there are only 3 lamps). Original lighting system, which was on parking to the end of March 2018 was realised by Thorn Riviera. Comparing parameters of the new and old lighting system especially efficiency and power consumption clearly shows benefits of LED lighting system Tab.1.

\section{Table 1 -Technical description of luminaires installed on polygon Broadband light}

\begin{tabular}{|c|c|c|c|c|}
\hline \multirow{2}{*}{$\begin{array}{l}\text { Quantitative and qualitative } \\
\text { parameters }\end{array}$} & \multicolumn{4}{|c|}{ Luminaire } \\
\hline & \begin{tabular}{|l|} 
Naica \\
(Boss)
\end{tabular} & \begin{tabular}{|l|}
$\mathrm{R} 2 \mathrm{~L} 2$ \\
(Thorn)
\end{tabular} & \begin{tabular}{|l} 
Teceo \\
(Schreder)
\end{tabular} & $\begin{array}{l}\text { Riviera } \\
\text { (Thorn) }\end{array}$ \\
\hline Luminous flux $\Phi(\mathrm{lm})$ & 20640 & 11706 & 15410 & 11270 \\
\hline Power P (W) & 167 & 91 & 124 & 170 \\
\hline Specific power la. $\eta\left(\mathrm{lm} \cdot \mathrm{W}^{-1}\right)$ & 124 & 128 & 124 & 66 \\
\hline Efficiency (\%) & 86 & - & 86 & 64,4 \\
\hline $\mathrm{Ra}(-)$ & 70 & 70 & 70 & 25 \\
\hline $\mathrm{Tc}(\mathrm{K})$ & 4000 & 4000 & 4000 & 2000 \\
\hline $\mathrm{T}(\mathrm{h})$ & 100000 & 100000 & 100000 & 32000 \\
\hline IP (optics/la.) & $66 / 66$ & $66 / 66$ & $66 / 66$ & $66 / 44$ \\
\hline $\mathrm{IK}(-)$ & 10 & 8 & 8 & 7 \\
\hline Protection class (-) & 1 & 1 & $1(2)$ & 2 \\
\hline
\end{tabular}




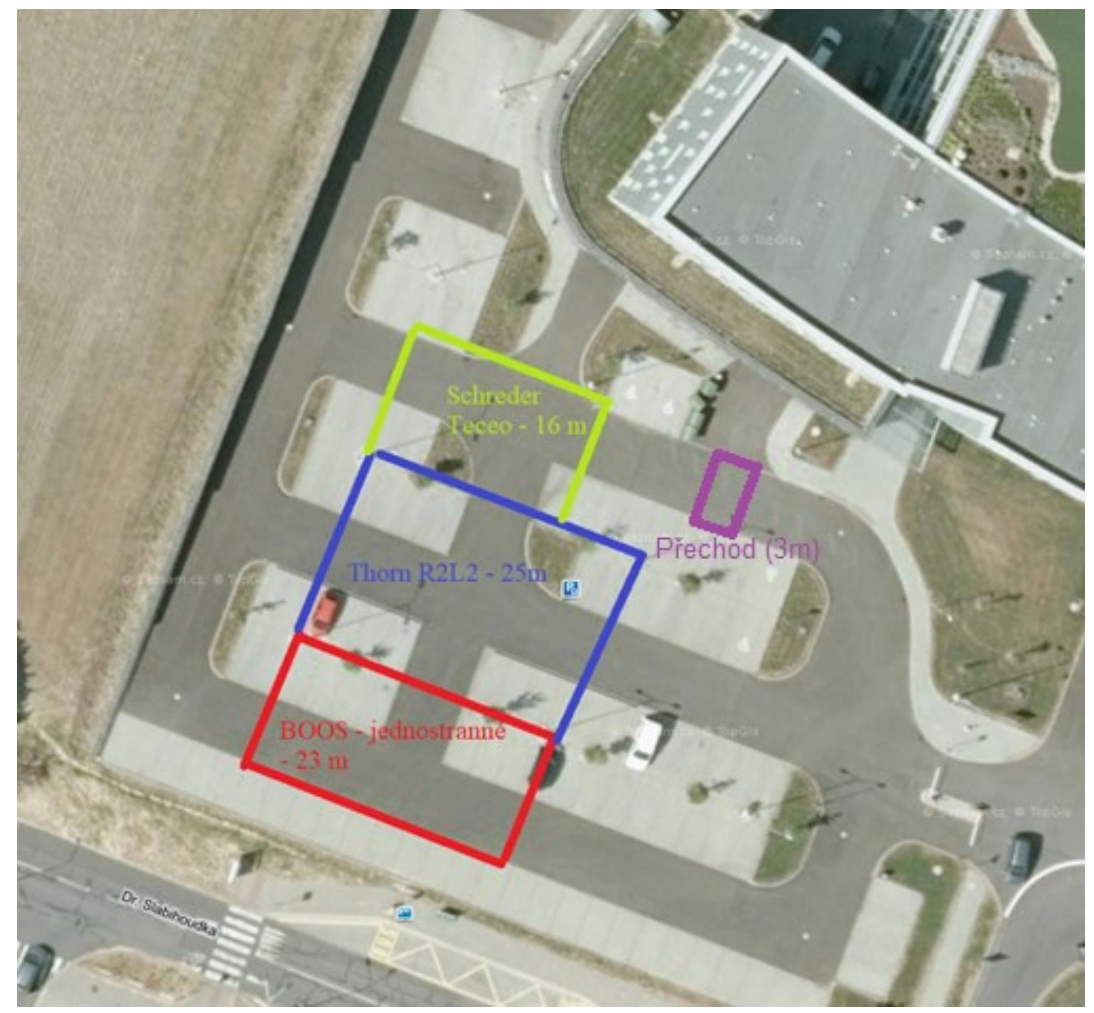

Figure 1 - Demonstration of sections with installed lights of individual companies on the polygon Broadband light

Individual luminaire spacing Naica, R2L2 and Teceo were by norm ČSN EN 13201- 2 placed to the highest class of lighting M1. Relevant parameters determining a particular lighting class were deliberately selected as the highest, in order to dim the test polygon. Dimming will be performed on lighting classes M2, M3, P1 and others to demonstrate energy savings and testing of the control system used. The regulation of light intensity consider with the maximum safety on the communication.

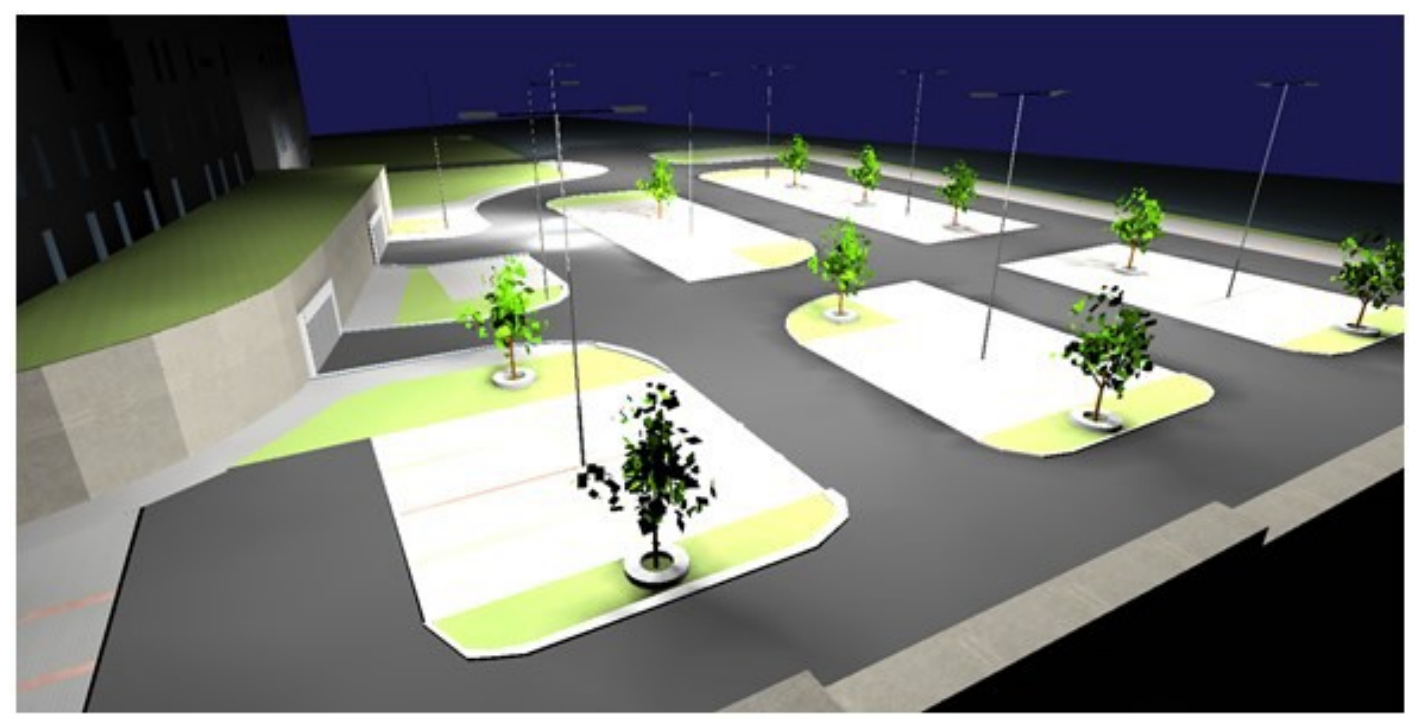

Figure 2 - Light technical model of polygon Broadband light

During polygon construction was made complex lighting and technical calculations [2]. They were made in Relux Pro application. Also was made complex lighting and technical model of polygon of faculty Electronic and Computer science University of Báňská, which takes into 
account all surface reflectance Figure.2. Model will be used for correlation of each states during lighting system control with real measured situations.

\subsection{Broadband light LED driver}

BroadbandLIGHT LED driver based on Ethernet communication standard allows the technology to enter real operation, respectively allow remote regulation and lighting management of all power classes based on Ethernet standard and protocol of application layer MQTT (Message Queuing Telemetry Transport), this ensure connection of device using existing power line (transfer technology of OFDM) and allow electronic communication data transfer using light intensity in the visible range of radiation(back data transfer in IR spectre or using unlicensed radio frequency RF band 2.402 to $2.480 \mathrm{GHz}$ )

\subsection{Power LED modulator based on Bias-T}

Power LED modulator based on bias $T$ is constructed for target operating point values of $I D C \max =1 \mathrm{~A}$ and $\mathrm{UDC} \max =150 \mathrm{~V}$ with lowest frequency fmin=2 $\mathrm{MHz}$ and at the same time minimal bandwidth $B=100 \mathrm{MHz}$. These parameters of bias $\mathrm{T}$ allows deployment of chipset technology BPL working in frequency band 2 to $34 \mathrm{MHz}$, this enable transfer speed of $100 \mathrm{Mbps}$ (OFDM 16/64-QAM). Bias T power LED modulator using this construction allow transfer of information using visible light spectre at real LED lamps from all power classes.

\subsection{Electric quality measurement}

Electric power quality measurement is based on virtual instrumentation. The base idea of developer device is to measure and analyse electric energy quality using norms ČSN EN 50160 and ČSN EN 61000. Measurement system itself consist of chassis NI cDAQ-9185, universal voltage measurement card NI-9205, current to voltage converters CVC-25/12.5 andvoltage to voltage isolation converters VVC-600/300Figure.3. Outputs of these converters are connected to input of measurement card and as next step are these data processed using virtual measurement device with regard to the above mentioned standards.

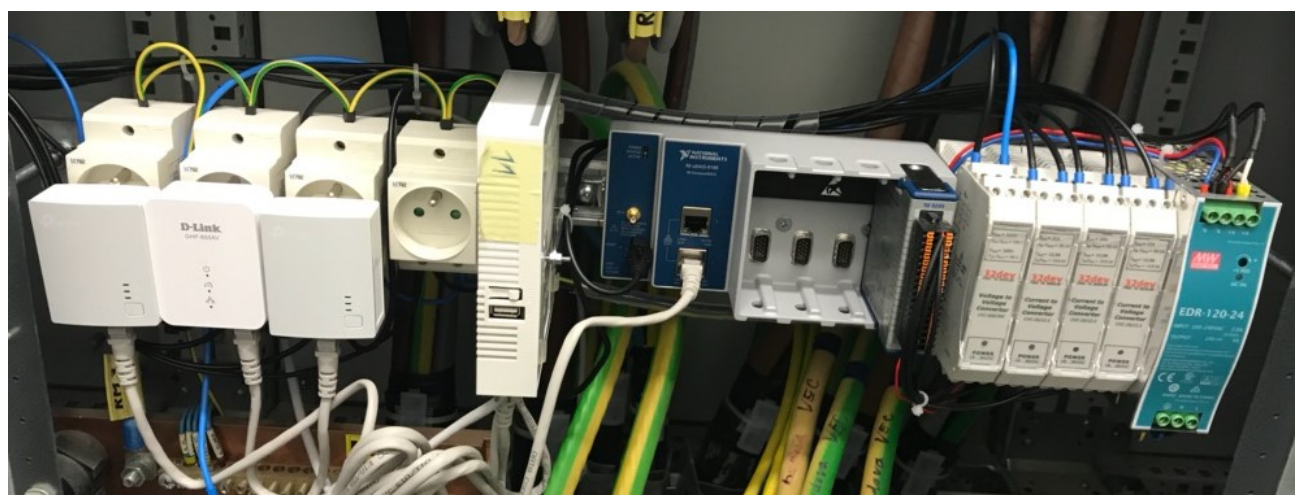

Figure 3 - Measurement system realization

\section{Polygon management system}

It is a real implementation of the whole technological unit BroadbandLIGHT at the testing polygon of the Faculty of Electrical Engineering and Computer Science, VŠB-TUO, within the registered pilot plant with name Controlling system based on wide band communication using light including smart technologiesFigure.4. An integral part of the pilot plant is the deployment of unique control software, which was officially registered under the name of Software for remote control of luminaires based on wideband communication Broadband ${ }^{\text {LIGHT}}$. 


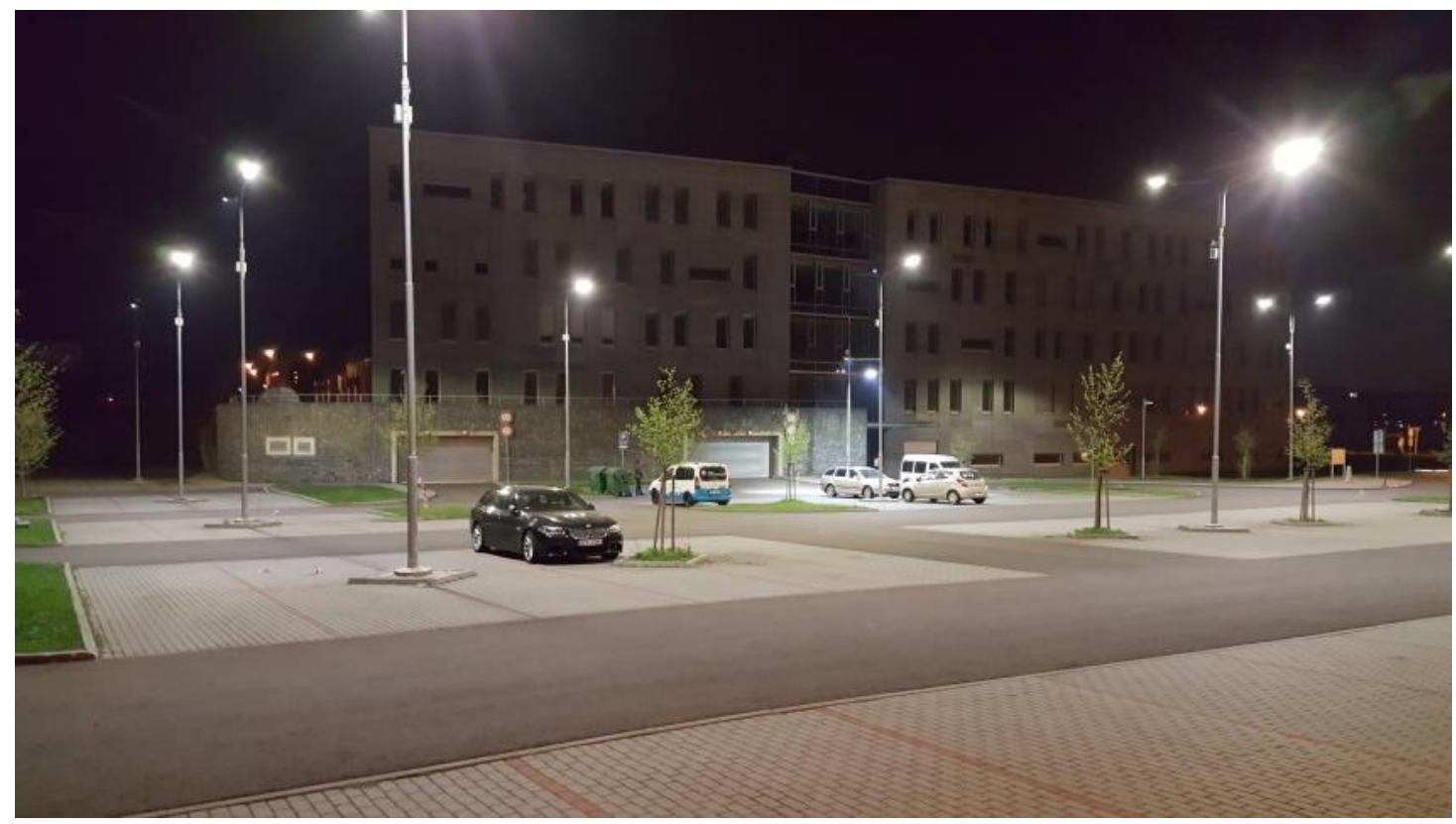

Figure 4 - Actual state of Broadband light technology

\subsection{Software for lamp remote control}

Luminaire remote control software is based on wide band communication Broadband light [4].

All of BroadbandLIGHT's key capabilities and features are based on the MQTT protocol, and the control applications here form a separate and independent layer separate from the information transfer. This solution enables centralized management within the web environment using server-side and browser-side technology. Applications are structured according to multilayer architecture, where backend systems are separated (Redis, SQL database, MQTT - ASGI and MQTT - DALI over TCP) Figure.5. The control application itself works in the environment of Apache, Nginx, Daphne, and presentation layer of ISO / OSI (Websocket, Apache, browser). Such a solution provides a very good division of the individual functional parts both in terms of security and in terms of functionality and data distribution over the entire BroadbandLIGHT system [1] Figure.6,Figure.7.

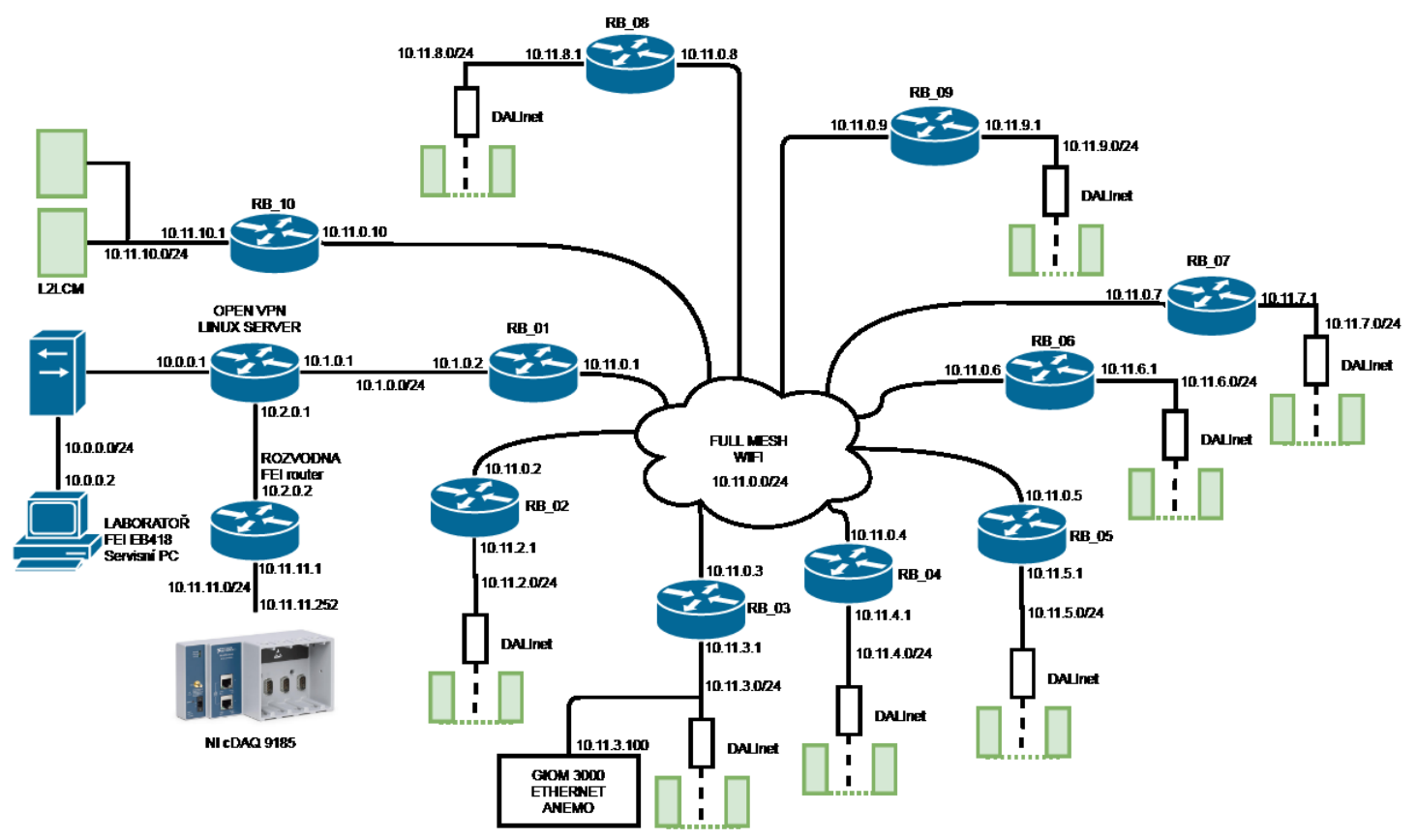

Figure 5 - Polygon data communication topology 

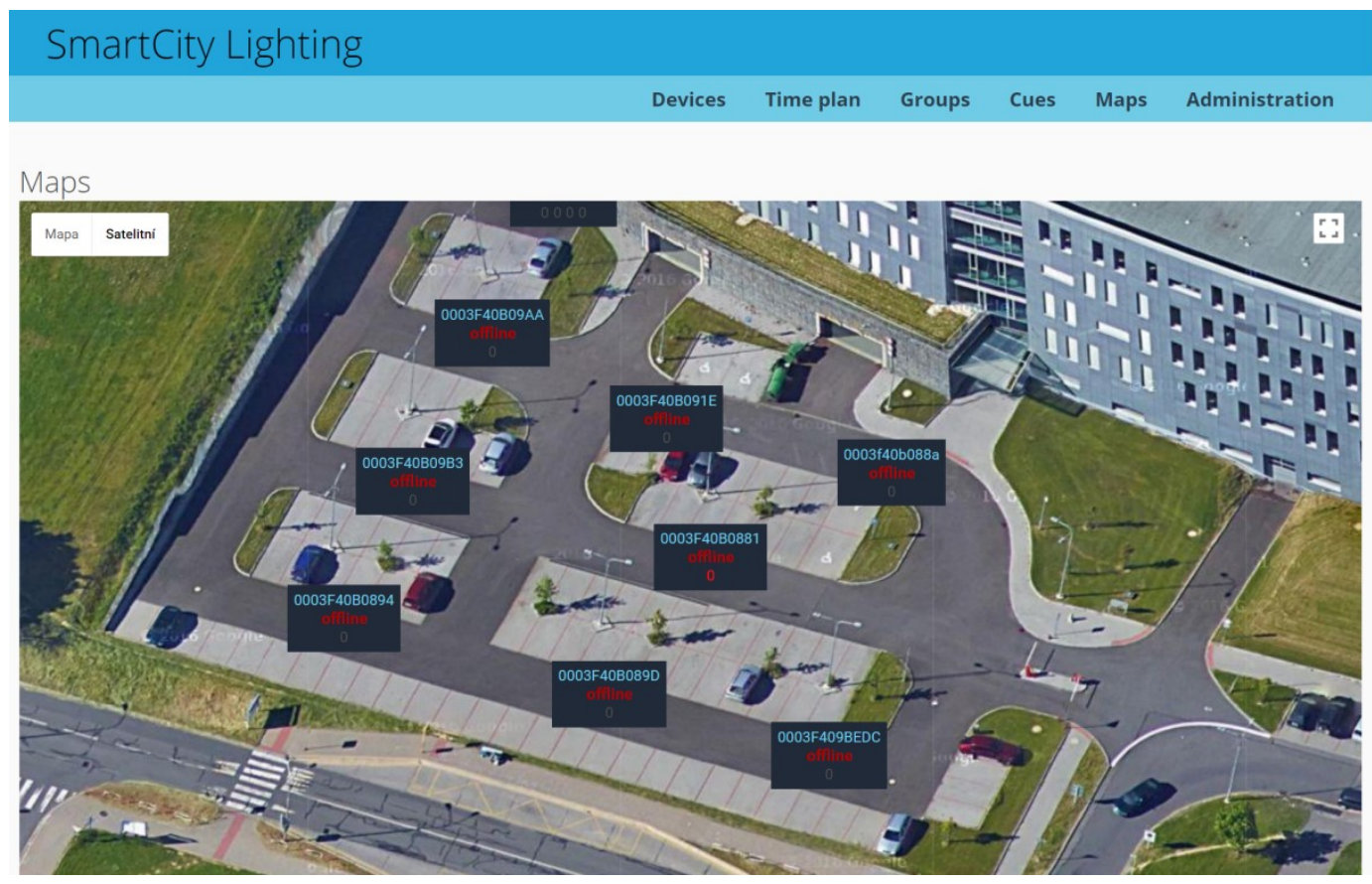

Figure 6 - Initial window of software for control of test polygon showing actual status of luminaires

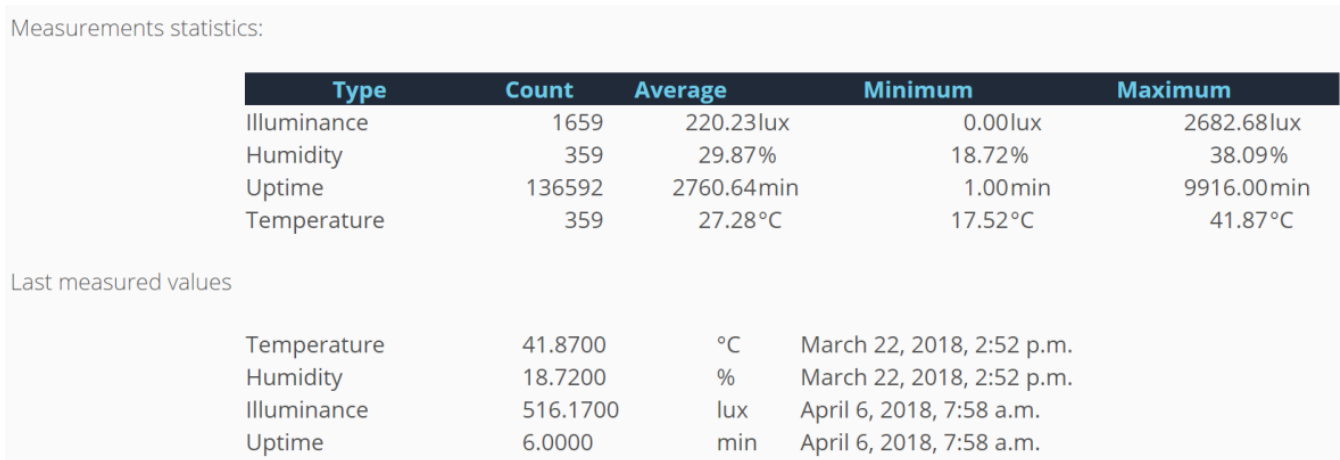

Figure 7 - Detailedinformation about actual state of polygon including statistics

\subsection{Software for central management of polygon and "smart" devices}

Software for centralized remote control of individual technologies falling into category of SMART [3].

The primary goal of the developed application is to implement of components from different manufacturers (National Instruments, AXIS, Dahua, own production) into one comprehensive control application. It is designed for long-term measurement, control and monitoring of the BroadbandLIGHT test polygonFigure.8. The application architecture mainly includes a producer-consumer plugin solution for easy extensibility and overall application modularity. The plugins include the official NI DAQmx toolkits, the Electrical Power Quality toolkit, the NI Adaptive Filter toolkit, the DAQ.io MQTT toolkit, and our own library of functions for communicating between individual plugins. 


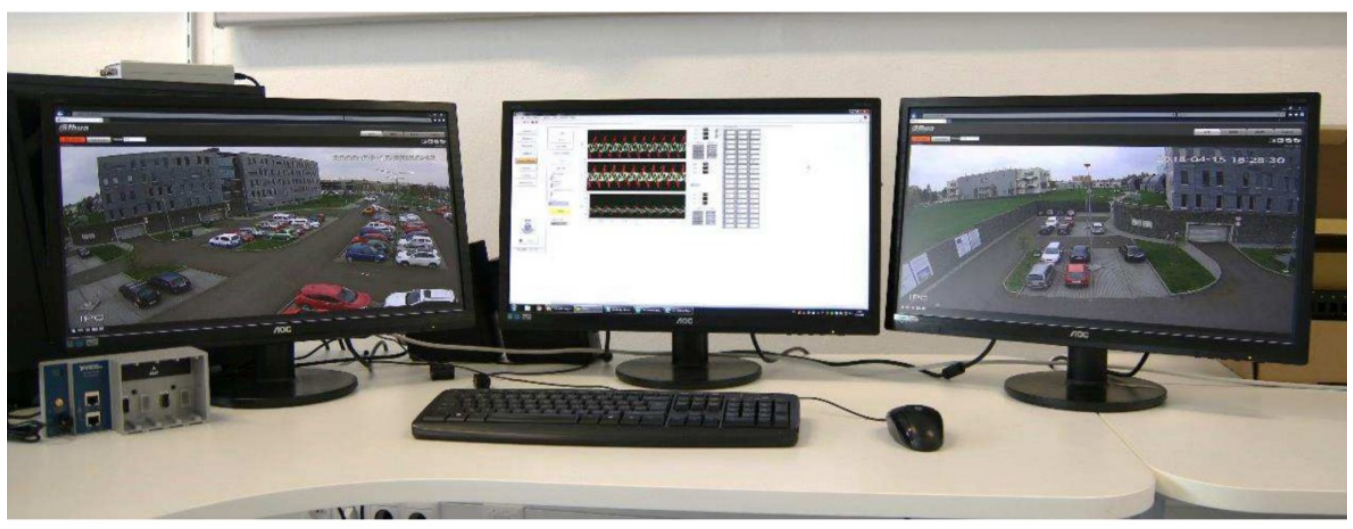

Figure 8 - Look on control centre for polygon Broadband light

The application as its main part contains measurement and calculation of electric power quality based on ČSN EN 50160 standard. Between parameters which are calculated fall mainly harmonic distortion, distortion of higher harmonic signals, measurement of long term and short term flicker and also aggregation of measured and calculated data, calculating average value for some time period and sending data to file for storing on disc.

Plugin of smart devices you can see on Figure.9 and Figure.10, where is meteorological station and camera system shown.

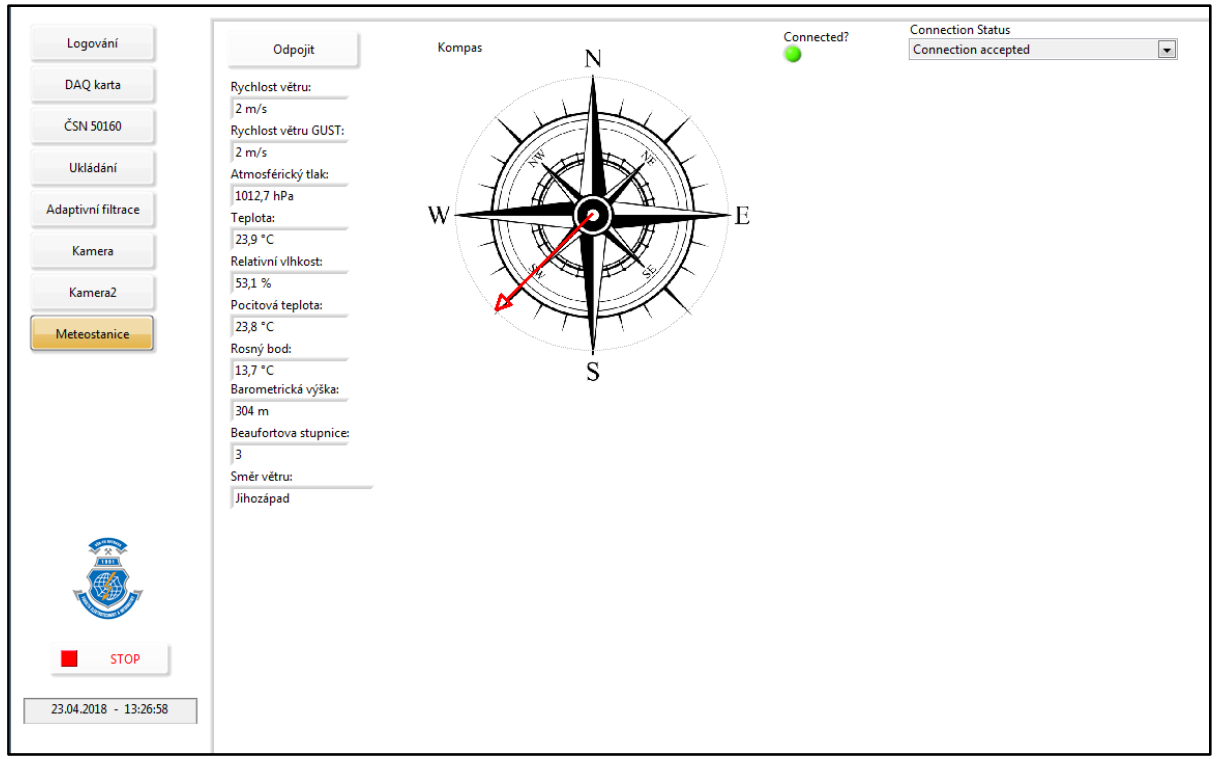

Figure 9 - Front panel with meteorological station plugin 


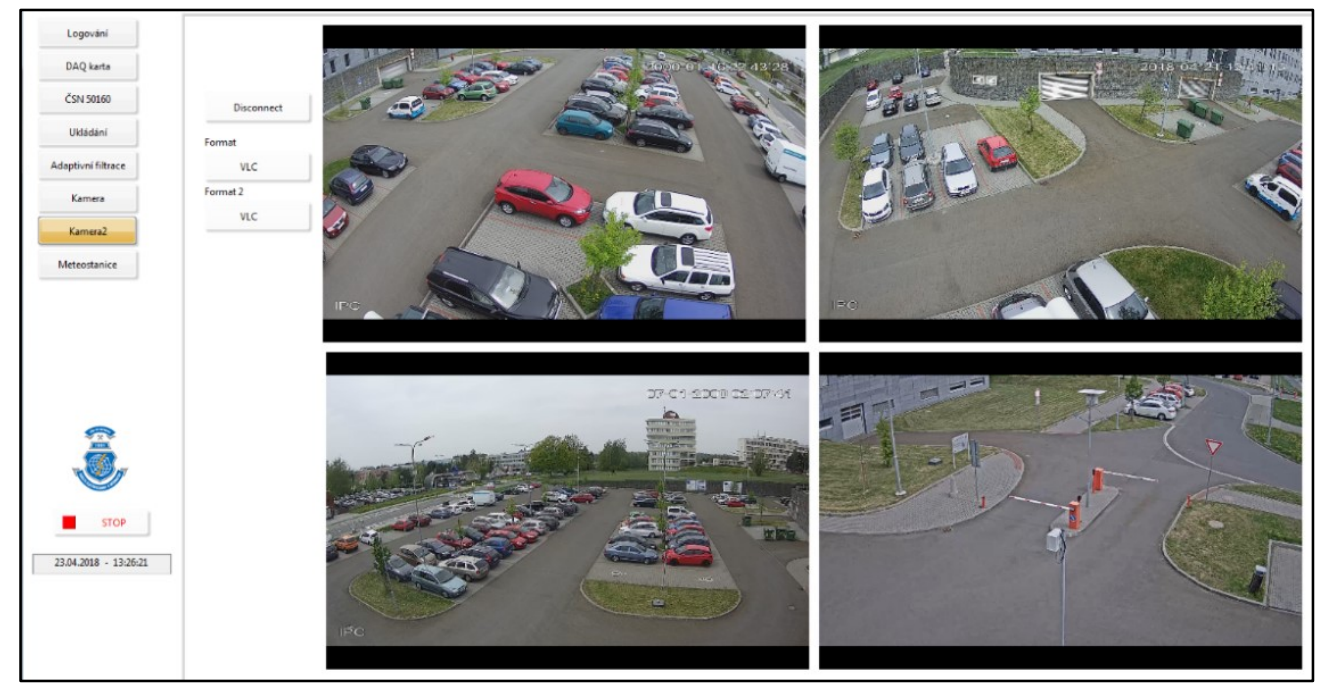

Figure 10 - Front panel with camera system plugin

\section{Another future activities}

Using PL network as source of electric energy

- Installation of small photo voltaic electric station on PL pole, which can during day supply energy to meet the requirements of smart technologies

Extend polygon with display unit and dynamic active traffic signs

- Dynamic signs on PL can be effective in increasing traffic safety at night

- Display units can work as on-line delivery of important information's, possibly for advertising

Extending PL on possibility of smart charging

- Power sockets with tarification and online payment on lamp poles (max 4A - mobile phone, laptop or small electronic)

- Electro mobile cars charging near to main switchboard of PL

\section{Conclusion}

The project of test polygon Broadband light is actual fullyoperational, including the above described technologies that have been deployed and their functionality has been verified. Automatic lighting control of luminaires is provided by our own registered Software for remote control of luminaires based on wideband communication Broadband LIGHT. There was a comparative measurement of consumption, distortion of power supply and lighting parameters of the old installation (sodium lamps) and newly installed luminaires (LED) when all parameters have to significantly improvedminimally $2 x$ Tab.1. By comparing the parameters of the new LED luminaires, the Thorn R2L2 luminaire would be the best for the purpose of the City of Ostrava because of the lowest energy consumption of $91 \mathrm{~W}$ at a still very good luminous flux of $11706 \mathrm{Im}$ (the best luminaire power of $128 \mathrm{Im} / \mathrm{W}^{-1}$ ). Currently, the polygon Broadband light serves not only the city of Ostrava as a testing and comparative workplace of LED lighting fixtures but also as a training model for testing the light technical parameters for students and last but not least, for the development and testing of new "smart" technologies. Currently there are camera security systems, audio system, weather station and small charging station in the polygon network. In the coming time, the system will be upgraded by adding photovoltaic power station panels mounted to the top of PL poles, system of automatic lamplight parameters control using surrounding weather conditions and system for navigation of arriving cars to free parking places. 


\section{Thanks}

On project polygon Broadband light cooperate:

- Ministry of Internal things of the Czech Republic - project - Analyse of visibility of road users in order to increase their safety at dusk and at night

- TAČR - project - PRESEED - Broadband for Smart City - Use of public lighting infrastructure to cover the urban area with Smart Technologies

- Ostrava Communicationsa.s. - technical support

- Czech society for lightingregional group Ostrava - project and financial support

- Zumbtobel group - delivery of luminaires

- ArtechnicSchréder - delivery of luminaires

- Boos lighting - delivery of luminaires

- MSV electronic - display unit

- Led2led - luminaire development

- AXIS communication -camera and audio system

\section{References}

[1] ZHANG, Jun, Guifang QIAO, Guangming SONG, Hongtao SUN a Jian GE. 2013. Group decision making based autonomous control system for street lighting. Measurement [online].46(1), 108-116, DOI: 10.1016/j.measurement.2012.05.025. ISSN 02632241.

[2] VINH, Quang Trinh, Tran Quoc KHANH, Hristo GANEV a Max WAGNER. 2014. Measurement and Modeling of the LED Light Source. LED Lighting [online]. Weinheim, Germany: Wiley-VCH Verlag GmbH \& Co., 2014-11-28, s. 133-232. DOI: 10.1002/9783527670147.ch4. ISBN 9783527670147.

[3] JIANG, Peng, Hongbo XIA, Zhiye HE a Zheming WANG. 2009. Design of a Water Environment Monitoring System Based on Wireless Sensor Networks. Sensors [online].9(8), 6411-6434. DOI: 10.3390/s90806411. ISSN 1424-8220.

[4] NIPPUN KUMAAR, A.A, G KIRAN a TSB SUDARSHAN. 2010. Intelligent Lighting System Using Wireless Sensor Networks. International Journal of Ad hoc, Sensor \& Ubiquitous Computing [online].1(4), 17-27. DOI: 10.5121/ijasuc.2010.1402. ISSN 09761764. 